\title{
The relationship between serum levels of prolactin and growth hormone in the early postnatal period
}

\author{
Jonathan Daliot ${ }^{1}$, Tami Laron-Kenet ${ }^{2}$, Mohammad Wattad ${ }^{3}$, Anat Ben-Dor ${ }^{3}$, Pearl Lilos ${ }^{1}$ and Zvi Laron ${ }^{1}$
}

BACKGROUND: In the neonatal period, the pituitary hormones including prolactin (PRL) and human growth hormone $(\mathrm{hGH})$ are secreted in high amounts due to immature feedback mechanisms. As both hormones are secreted in part by the same somatomammotrophic cells, we investigated their relationship in newborns with respect to sex, gestational week, method of delivery, and anthropometric data.

METHODS: The serum levels of PRL and hGH were measured in blood drawn from 225 newborns. The newborn data were extracted from medical records.

RESULTS: A positive correlation was found between logtransformations of PRL and hGH ( $r=0.17 ; P=0.01 ; n=225)$, with a stronger correlation in newborns whose blood samples were taken more than 2 days after birth $(r=0.42 ; P<0.001$; $n=130$ ). Log-transformations of the PRL/hGH ratio demonstrated a positive correlation with the gestational week $(r=0.39 ; \quad P<0.001 ; \quad n=200)$. Multiple regression analysis showed that $15 \%$ of the variance in the logarithm of this ratio is attributed to the gestational week.

CONCLUSION: In newborns, serum PRL and hGH levels show a positive correlation that can be explained by common regulatory factors or a drift phenomenon. A higher gestational week is associated with a higher PRL/hGH ratio. Further studies are needed to look for possible confounders and to determine the PRL-hGH relationship in different conditions.

$\mathbf{P}$ rolactin (PRL) and human growth hormone (hGH) are pituitary hormones that affect proliferation and growth, high levels of which are known to be the risk factors for malignancy $(1,2)$. Fetal serum PRL levels rise gradually during pregnancy (3) and later decline in the first year of life. hGH is the main growth-stimulating hormone after birth (4). Prenatally, two of its variants, hGH-V and human placental lactogen (hPL), produced by placental syncytiotrophoblasts, regulate fetal development together with fetal pituitary hGH and insulin-like growth factor-1 (IGF-1) $(5,6)$. Serum hGH levels are higher in preterm newborns than in the full-term infants (7). In the early postnatal period (0-28 days of life), pituitary hormones including PRL and hGH are secreted in large amounts, probably due to a delay in the maturation of the negative-feedback mechanisms (8). Pituitary somatomammotrophic cells that co-secrete PRL and hGH are already recognizable in the anterior pituitary early in fetal development $(9,10)$ and contain secretory granules that can be either mono- or bi-hormonal $(11,12)$. It has been suggested that somatomammotrophs function as an intermediate in the process of transdifferentiation between somatotrophs and lactotrophs (13). PRL and hGH share several stimulatory factors (e.g., thyrotropin-releasing hormone, hypoglycemia, and physical stress) and inhibitory factors (e.g., dopamine, somatostatin, and obesity) (4,14-16). Likewise, some molecules have a different effect on the two hormones (e.g., IGF-1). Publications on the relationship between the secretion of PRL and hGH in different conditions are scant. Concomitant measurements of both hormones were performed in patients with acromegaly (17), prolactinomas (18), pituitary adenomas that secrete both hormones (19), Parkinson's disease (20), obesity (21), and Laron syndrome (22). Few studies report simultaneous measurements of these hormones in the postnatal period $(23,24)$. The aim of this study was to investigate the PRL-hGH relationship in a large number of newborns with respect to sex, length of gestation, method of delivery, and anthropometric data.

\section{METHODS}

This study was approved by the Institutional Review Board at Rabin Medical Center (Petach Tikva, Israel).

\section{Subjects \\ A total of randomly selected 225 infants aged 0-27 days (mean \pm $\mathrm{SD}=2.43 \pm 3.84$ ) born in the Helen Schneider Hospital for Women (Petach Tikva, Israel) between June 2015 and July 2016 were included in this study. These infants were admitted to the Neonatal Intensive Care Unit at Schneider Children's Medical Center (Petach Tikva, Israel) or to the Newborn Department at Helen Schneider Hospital for Women. The subjects were included regardless of their gestational age (24-42-week gestation). There were no exclusion criteria.}




\section{Measurements}

Serum levels of PRL and hGH were measured by means of solidphase, two-site chemiluminescent immunoassays (Siemens Immulite 2000 Immunoassay System, Erlangen, Germany). The serum samples were taken from the remaining blood collected for a variety of reasons in the neonatal units, and were kept at $-20^{\circ} \mathrm{C}$ until analyzed. Whenever available, the following clinical and anthropometric data were extracted from medical records in the hospitalizing unit: sex, gestational week, method of delivery, birth weight, length and head circumference, birth of a twin sibling, and known medical diagnoses of the newborn and its mother.

\section{Data Analysis}

The values of PRL and hGH, as well as PRL/hGH ratios, were logtransformed to achieve a Gaussian distribution for further analysis. Pearson's correlation coefficients were calculated to determine the correlations between continuous values such as the logarithms of hGH and PRL. One-way ANOVA and Tukey's post hoc test were performed to determine differences between the mean values of the $\mathrm{PRL} / \mathrm{hGH}$ ratio logarithm among different categorical subgroups. A stepwise multiple regression analysis was performed with the $\mathrm{PRL} / \mathrm{hGH}$ ratio logarithm as a dependent variable to determine the possible predictors of this ratio. Statistical tests were performed using IBM SPSS Statistics (Version 23, Armonk, NY, USA).

\section{RESULTS}

\section{Demographic Data}

The demographic data for newborns included in this study are summarized in Table 1.

\section{Overall Analysis}

A significant positive correlation was found between logarithms of PRL and hGH in blood samples taken 2-27 days after birth $(r=0.42 ; P<0.001 ; n=130)$. A weaker correlation was found when the samples taken in the first 2 days of life were included $(r=0.17 ; P=0.01 ; n=225)$ (Figure 1). The logarithm of the $\mathrm{PRL} / \mathrm{hGH}$ ratio had a significant positive correlation with the gestational week $(r=0.39 ; P<0.001$; $n=200$; Figure 2). Stepwise multiple regression analysis showed that $15 \%$ of the variance in the $\mathrm{PRL} / \mathrm{hGH}$ ratio logarithm can be attributed to the gestational week (Table 2).

\section{The Hormonal Relationship in Different Subgroups}

The data collected between 2 and 27 days after birth were further analyzed by dividing the newborns into female and male subgroups, and into preterm (gestational week $<37$ weeks) and term subgroups. Females demonstrated a stronger correlation between logarithms of PRL and hGH $(r=0.5 ; P<0.001 ; n=63)$ than males $(r=0.39 ; P<0.001$; $n=67)$ (Figure 3). Differences between the preterm $(r=0.4$; $P=0.01 ; n=48)$ and term $(r=0.43 ; P<0.001 ; n=66)$ infants were not significant.

\section{The Hormonal Ratio in Different Subgroups}

Table 3 summarizes the mean values of the PRL/hGH ratio logarithm in different methods of delivery. One-way ANOVA

Table 1. Available demographic data for newborns included in this study

\begin{tabular}{lc}
\hline Sex $(n)$ & 118 \\
Males & 107 \\
Females & $24-42,37.66 \pm 2.64$ \\
Gestational week $^{\mathrm{a}}$ (range, mean \pm SD) & \\
Measurements (range, mean \pm SD) & \\
Weight $^{\mathrm{b}}(\mathrm{g})$ & $710-4356,2956.02 \pm 632.76$ \\
Length $^{\mathrm{c}}(\mathrm{cm})$ & $42-54,48.72 \pm 2.64$ \\
Head circumference $^{\mathrm{d}}(\mathrm{cm})$ & $21.5-37.5,33.52 \pm 2.15$ \\
Twins $^{\mathrm{a}}(n)$ & 25
\end{tabular}

\begin{tabular}{|c|c|}
\hline Method of delivery ${ }^{\mathrm{b}}$ & \\
\hline Vaginal & 123 \\
\hline Assisted vaginal & 16 \\
\hline Cesarean & 62 \\
\hline
\end{tabular}

a Data were available for 200 newborns.

bData were available for 201 newborns.

'Data were available for 191 newborns.

${ }^{\mathrm{d}}$ Data were available for 196 newborns.
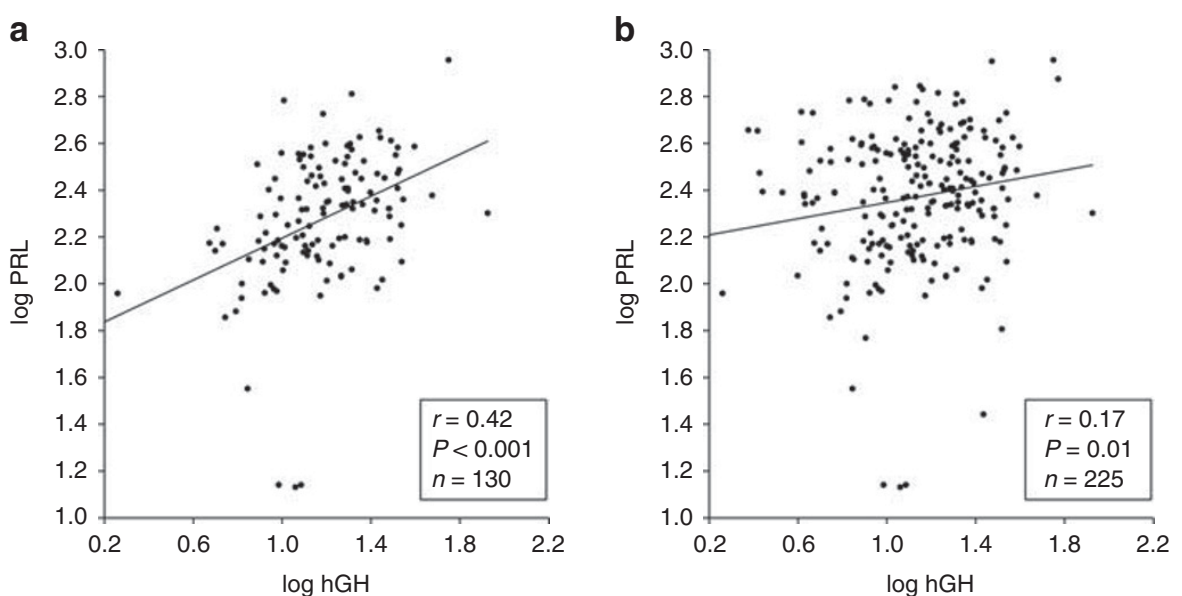

Figure 1. Scatterplots showing the correlation between logarithms of PRL ( $\mathrm{ng} / \mathrm{ml})$ and $\mathrm{hGH}(\mathrm{ng} / \mathrm{ml})$ measured during (a) 2-27 days after birth and (b) 0-27 days after birth. hGH, human growth hormone; PRL, prolactin. 


\section{Articles | Daliot et al.}

showed a significant difference between the values $(P=0.02)$, and Tukey's post hoc test revealed a significant difference between the vaginal delivery group mean value $(n=123$; mean $\pm \mathrm{SD}=1.28 \pm 0.39)$ and the cesarean section group mean value $(n=62$; mean $\pm \mathrm{SD}=1.15 \pm 0.3 ; P=0.04)$.

\section{DISCUSSION}

Concomitant determination of PRL and hGH in the early postnatal period, during which pituitary hormones are secreted in high amounts, has not been performed before in a large group of infants. Based on the fact that somatomammotrophic cells secrete both hormones, we tried to find out whether they share a common secretory pattern. The stronger correlation between logarithms of PRL and hGH that was calculated when samples from the first 2 days of life were excluded may be partially explained by a PRL surge that occurs in the first day of extra-uterine exposure (25), after

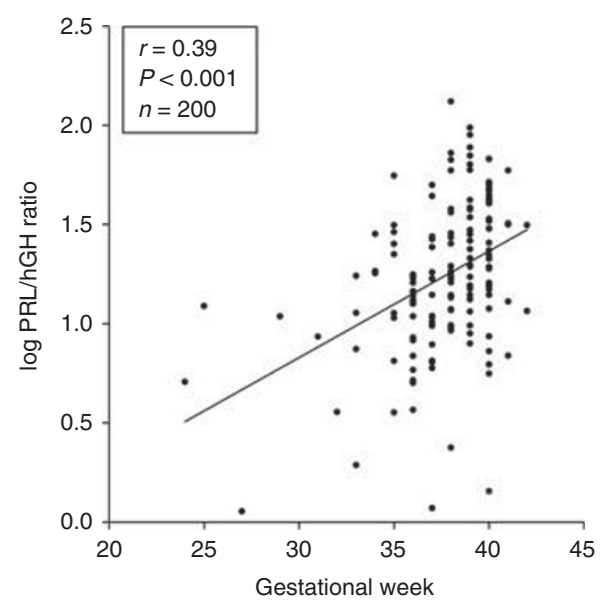

Figure 2. A scatterplot showing the correlation between the logarithm of the PRL $(\mathrm{ng} / \mathrm{ml}) / \mathrm{hGH}(\mathrm{ng} / \mathrm{ml})$ ratio and the gestational week. $\mathrm{hGH}$, human growth hormone; PRL, prolactin. which PRL levels decrease during the first postnatal week (26). Thus, the data collected in days 2-27 of life may represent PRL levels that are less affected by the delivery event. As physical stress elevates levels of both PRL and hGH, delivery-related stress may also affect measurements performed immediately after birth. This is demonstrated by our finding that the PRL/hGH ratio logarithm in the vaginal delivery group was significantly higher than that in the cesarean section group, and supports former evidence of significantly higher plasma PRL levels in infants after vaginal delivery than those after elective cesarean delivery (27). The differences in strength between correlations of PRL and hGH logarithms among male vs. female newborns may add further evidence that sex differences in pituitary hormone secretion exist already in the perinatal period. For example, Guyda and Friesen (28) reported significantly lower serum PRL levels in premature female infants when compared with those in the premature male infants, and Schmidt and Schwarz (29) found significant sex differences of luteinizing hormone (LH) and follicle-stimulating hormone (FSH) levels in newborns. The nervous system in the human neonate, in contradistinction to other mammals, continues to mature after birth, and the

Table 2. Stepwise multiple regression analysis for the logarithm of the PRL/hGH ratio.

\begin{tabular}{lcc}
\hline & Standardized coefficient $(\beta)$ & $P$-value \\
\hline Gestational week & 0.39 & $<0.001$ \\
Birth weight & Excluded & Excluded \\
Birth length & Excluded & Excluded \\
Birth head circumference & Excluded & Excluded
\end{tabular}

\begin{tabular}{lll} 
Overall & & \\
$R^{2}$ & 0.154 & - \\
Adjusted $R^{2}$ & 0.150 & - \\
\hline
\end{tabular}

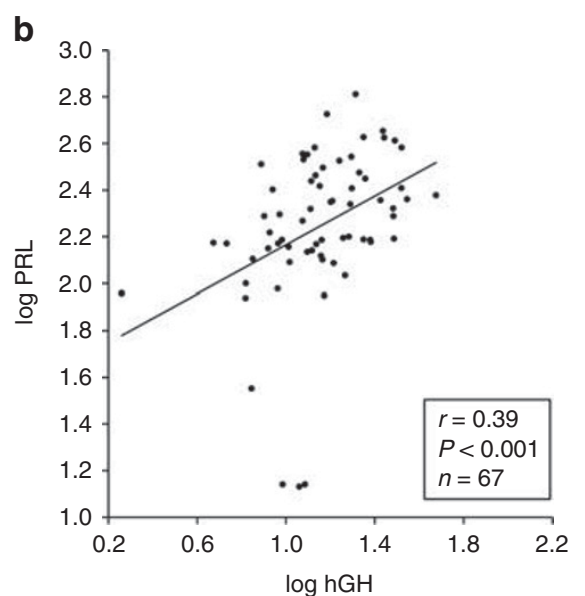

Figure 3. Scatterplots showing the correlation between logarithms of PRL $(\mathrm{ng} / \mathrm{ml})$ and $\mathrm{hGH}(\mathrm{ng} / \mathrm{ml})$ measured $2-27$ days after birth in (a) female newborns and in (b) male newborns. hGH, human growth hormone; PRL, prolactin. 
Table 3. Mean logarithms of the PRL $(\mathrm{ng} / \mathrm{ml}) / \mathrm{hGH}(\mathrm{ng} / \mathrm{ml})$ ratios in different methods of delivery

\begin{tabular}{lcc}
\hline Method of delivery & $n$ & Mean \pm SD \\
\hline Vaginal & 123 & $1.28 \pm 0.39$ \\
Assisted vaginal & 16 & $1.38 \pm 0.38$ \\
Cesarean & 62 & $1.15 \pm 0.30$ \\
\hline
\end{tabular}

development of the pituitary hormone feedback mechanisms is delayed (30). The bi-hormonal somatomammotrophs may take part in this developmental process. It will be of interest to determine the behavior of PRL during states of hGH deficiency as well as stress in newborns. A possible clinical implication of the postnatal PRL-hGH correlation can be the enhancement of joint actions by both hormones like cell proliferation (4).

\section{CONCLUSIONS}

In summary, our findings indicate a significant positive correlation between early postnatal serum PRL and hGH levels that is higher among females, supporting either common regulatory factors or a drift phenomenon involving the somatomammotrophic cells. The postnatal high levels of pituitary hormones can be the result of delivery stress or delay in the maturation of the feedback mechanisms. Of all measured parameters in this study, the gestational week at birth was shown to be the strongest determinant of the PRL/ hGH ratio, which was also affected by the method of delivery. Our study may indicate that the preferable time to evaluate PRL and hGH in newborns is after the first 2 postnatal days, when the secretion of both hormones is less affected by the delivery event. Further studies are needed to look for possible confounders and to determine the PRL-hGH relationship in different conditions, in particular the ones in which levels of one hormone are known to be high.

\section{ACKNOWLEDGMENTS}

This work was performed in partial fulfillment of the M.D. thesis requirements of the Sackler Faculty of Medicine, Tel Aviv University, Tel Aviv, Israel.

\section{STATEMENT OF FINANCIAL SUPPORT}

The authors did not receive any financial support relevant to this article.

Disclosure: The authors declare no conflict of interest.

\section{REFERENCES}

1. Chae HW, Kim DH, Kim HS. Growth hormone treatment and risk of malignancy. Korean J Pediatr 2015;58:41-6.

2. Tikk K, Sookthai D, Fortner RT, et al. Circulating prolactin and in situ breast cancer risk in the European EPIC cohort: a case-control study. Breast Cancer Res 2015;49:49.

3. Freemark M. The roles of growth hormone, prolactin, and placental lactogen in human fetal development. In: Handwerger S, ed. Molecular and Cellular Pediatric Endocrinology, 1 edn. Totowa, NJ: The Humana Press, 1999:60.

4. Kaiser U, Ho KK. Pituitary physiology and diagnostic evaluation. In: Melmed S, Polonsky KS, Larsen PR, Kronenberg H, eds. Williams
Textbook of Endocrinology, 13th edn. Philadelphia, PA: Elsevier, 2016:182-199.

5. Frankenne F, Closset J, Gomez F, Scippo ML, Smal J, Hennen G. The physiology of growth hormones (GHs) in pregnant women and partial characterization of the placental GH variant. J Clin Endocrinol Metab 1988;66:1171-80.

6. Handwerger S, Freemark M. The roles of placental growth hormone and placental lactogen in the regulation of human fetal growth and development. J Pediatr Endocrinol Metab 2000;13:343-56.

7. Hawkes CP, Grimberg A. Measuring growth hormone and insulin-like growth factor-I in infants: what is normal? Pediatr Endocrinol Rev 2013;11:126-46.

8. Gluckman PD. Functional maturation of the neuroendocrine system in the perinatal period: studies of the somatotropic axis in the ovine fetus. J Dev Physiol 1984;6:301-12.

9. Asa SL, Kovacs K, Laszlo FA, Domokos I, Ezrin C. Human fetal adenohypophysis. Histologic and immunocytochemical analysis. Neuroendocrinology 1986;43:308-16.

10. Dubois PM, Hemming FJ. Fetal development and regulation of pituitary cell types. J Electron Microsc Tech 1991;19:2-20.

11. Hoeffler JP, Boockfor FR, Frawley LS. Ontogeny of prolactin cells in neonatal rats: initial prolactin secretors also release growth hormone. Endocrinology 1985;117:187-95.

12. Takahashi S. Development and heterogeneity of prolactin cells. Int Rev Cytol 1995;157:33-98.

13. Vidal S, Horvath E, Kovacs K, Lloyd RV, Smyth HS. Reversible transdifferentiation: interconversion of somatotrophs and lactotrophs in pituitary hyperplasia. Mod Pathol 2001;14:20-8.

14. Lamberts SW, Macleod RM. Regulation of prolactin secretion at the level of the lactotroph. Physiol Rev 1990;70:279-318.

15. Freeman ME, Kanyicska B, Lerant A, Nagy G. Prolactin: structure, function, and regulation of secretion. Physiol Rev 2000;80:1523-631.

16. Kanasaki H, Oride A, Mijiddorj T, Kyo S. Role of thyrotropin-releasing hormone in prolactin-producing cell models. Neuropeptides 2015;54: 73-7.

17. Schindel B, Ashkenazi I, Keret R, et al. Effect of octreotide on 24- hour growth hormone and prolactin secretory patterns in acromegalics. Horm Res 1991;36:209-15.

18. Lim JS, Ku CR, Lee MK, Kim TS, Kim SH, Lee EJ. A case of fugitive acromegaly, initially presented as invasive prolactinoma. Endocrine 2010;38:1-5.

19. Dessimoz C, Browaeys P, Maeder P, et al. Transformation of a microprolactinoma into a mixed growth hormone and prolactinsecreting pituitary adenoma. Front Endocrinol 2012;2:116.

20. Aziz NA, Pijl H, Frölich M, Roelfsema F, Roos RA. Diurnal secretion profiles of growth hormone, thyrotrophin and prolactin in Parkinson's disease. J Neuroendocrinol 2011;23:519-24.

21. Birketvedt GS, Geliebter A, Kristiansen I, Firgenschau Y, Goll R, Florholmen JR. Diurnal secretion of ghrelin, growth hormone, insulin binding proteins, and prolactin in normal weight and overweight subjects with and without the night eating syndrome. Appetite 2012;59:688-92.

22. Laron $Z$. The growth hormone-prolactin relationship: a neglected issue. Pediatr Endocrinol Rev 2011;9:546-8.

23. Beratis NG, Varvarigou A, Makri M, Vagenakis AG. Prolactin, growth hormone and insulin-like growth factor-I in newborn children of smoking mothers. Clin Endocrinol 1994;40:179-85.

24. De Zegher F, Van Den Berghe G, Devlieger H, Eggermont E, Veldhuis JD. Dopamine inhibits growth hormone and prolactin secretion in the human newborn. Pediatr Res 1993;34:642-5.

25. Sack J, Fisher DA, Wang CC. Serum thyrotropin, prolactin, and growth hormone levels during the early neonatal period in the human infant. J Pediatr Endocrinol Metab 1976;89:298-300.

26. Winters AJ, Colston C, MacDonald PC, Porter JC. Fetal plasma prolactin levels. J Clin Endocrinol Metab 1975;41:626-9. 


\section{Articles | Daliot et al.}

27. Heasman L, Spencer JA, Symonds ME. Plasma prolactin concentrations after caesarean section or vaginal delivery. Arch Dis Child Fetal Neonatal Ed 1997;77:F237-8.

28. Guyda HJ, Friesen HG. Serum prolactin levels in humans from birth to adult life. Pediatr Res 1973;7:534-40.
29. Schmidt H, Schwarz HP. Serum concentrations of LH and FSH in the healthy newborn. Eur J Endocrinol 2000;143:213-5.

30. Dattani MT, Gevers EF Endocrinology of fetal development. In: Melmed S, Polonsky KS, Larsen PR, Kronenberg H, eds. Williams Textbook of Endocrinology, 13 edn. Philadelphia, PA: Elsevier, 2016:849-892. 